\title{
GLOBAL CLIMATE CHANGE: A CHALLENGE TO URBAN INFRASTRUCTURE PLANNERS
}

Ted R. Miller, J. Christopher Walker, G. Thomas Kingsley, and William A. Hyman*

\begin{abstract}
Case studies suggest that a doubling of $\mathrm{CO}_{2}$ levels would require mainly urban infrastructure investments to ensure an adequate water supply and to prevent the rise in sea level from inundating coastal communities. Impacts likely would vary substantially by region. Cleveland, and presumably other Great Lakes cities, would appear likely to benefit from milder weather and not to experience substantial costs for infrastructure construction or management. An anticipated one meter rise in sea level probably would require diking and pumping or raising the land surface in many urban coastal areas, including more than half of the 20 largest metropolitan areas. The cost in Greater Miami probably would exceed $\$ 600$ million. It appears that inland cities need to be concerned primarily about water supply, electric power, and the possibility of increased subsidence problems.
\end{abstract}

\section{Considerable Warming Expected Within 100 Years}

Several weather models provide scenarios depicting possible global climate change (Smith and Tirpak, 1989). If they are correct, by 2080 , the Earth could be 3 to 5 degrees $\mathrm{C}$ warmer than today, hotter than it has been since the dinosaurs died out a million years ago. It would warm as much in 100 years as it has since the last glacial period 15,000 years ago. Since the Industrial Revolution started in 1850, the models suggest that enough $\mathrm{CO}_{2}$ and pollutants have been banked in the atmosphere to cause half that temperature rise. The rest would result from emissions projected over the next century. As the gases build up, effectively doubling current $\mathrm{CO}_{2}$ levels, the heat-reflectivity of the atmosphere should rise, making the Earth a considerably more powerful greenhouse.

With an average temperature rise of 5 degrees $\mathrm{C}$, temperatures could rise 10 degrees at the poles, but only modestly at the Equator. That could mean an end to the prevailing Westerly winds and major changes in ocean currents. Because of melting and thermal expansion, sea level could rise .5 to 1.5 meters by 2080 . Conversely, increased evaporation could lower lake levels; the Great

The Urban Institute, 2100 M St. NW, Washington, DC 20037 (202) $857-8600$
Lakes probably would fall almost as much as the seas would rise. The model estimates of precipitation are very preliminary; they suggest wetter winters, dryer summers, more droughts, and more stagnation events.

\section{Climate Change Could Have Major Impacts on Fixed Capital Stock}

Although actual practice varies, the nominal replacement cycle for most infrastructure is 30 to 50 years. Some water supply investments have 100 -year lives. Thus, infrastructure investments lock communities into capital stock for long periods and tend to make them vulnerable to rapid climate change. Changes in sea level, temperature, and precipitation patterns, for example, all could alter the water supply and demand balance between planned replacement cycles. The nature and pattern of precipitation could affect drainage requirements, as well as highway design and maintenance.

In coastal communities, a higher sea level could stimulate extensive construction of oceangates. Oceangates are coastal defense structures - dikes, levees, jetties, canals, locks, pumping systems. They prevent inundation by the sea, slow oceanfront erosion, control storm surges, reduce salt water intrusion into aquifers, and slow salt water advance up rivers. Currently, oceangates are such a minor category of infrastructure that they are not inventoried or included in needs assessments.

The heat wave of 1988 illustrated some of the potential infrastructure impacts.

-Hundred-degree weather expanded railroad tracks, forcing Amtrak to cut speeds from 200 to 128 kilometers per hour between Washington and Philadelphia (Bruske, 7/17/88) and may have contributed to a train wreck that injured 160 people on a Chicago-Seattle run ("Warped Rails", 8/7/88).

-A U.S. Army Corps of Engineers contractor worked around the clock for two weeks to build a 170-meter wide, 9-meter high silt wall across the bottom 40 percent of the Mississippi River channel 48 kilometers below New Orleans (Sossaman, 6/28/88, 7/15/88). This $\$ 2$ million wall slowed an advancing wedge of salt water that threatened the water supply in New Orleans 
and nearby parishes. It was designed to wash away when spring snow melt demands the full capacity of the channel.

-In Manhattan, heat exacerbated the effects of long-standing leaks in $256 \mathrm{~km}$ of steam pipes, causing the asphalt to soften. As vehicles kneaded the soft asphalt, thousands of bumps formed on city streets, requiring extensive repairs (Hirsh, 1988).

-In the suburbs of Washington, DC, steel expansion joints bubbled along a 13-mile stretch of I-66 (Lewis, 8/18/88).

\section{Case Studies Used to Examine Projected Urban Impacts}

This paper discusses some projected impacts of possible climate change on U.S. urban infrastructure. It focuses on case studies of the effects of water supply in New York City and on a variety of infrastructure in Miami and Cleveland.

The case studies were based on a critical review of infrastructure studies in the three cities, discussions of likely impacts with local infrastructure experts, analyses undertaken by these experts, and some preliminary calculations of potential impacts by the authors.

The temperature and precipitation effects of global climate change were estimated by applying the seasonal percentage changes indicated in two climate change models run for EPA (Jenne, 1988)-namely models of the impact of a doubling of atmospheric carbon dioxide developed by the Goddard Institute for Space Studies (GISS) and the Geophysical Fluid Dynamics Laboratory (GFDL) - to historical climate data from 1950-1980. Impacts on the number of heating and cooling degree days were computed as variations in average daily temperatures below and above 18.5 degrees $C$. Some of the conclusions were based on experience in cities where current temperatures are analogous to the projected temperatures in the cities under study, using the analogs identified by Kalkstein (1989).

Because the study was based on only three cities, it could not cover the full range of potential problems. The analyses had to be preliminary. They revealed infrastructure responses to global climate change that might be expensive, but they were not engineering analyses of the most cost-effective responses. The potential for reducing impacts through technological change also was not assessed.

\section{Miami Could Experience Severe, Costly Problems}

The Miami case study examined some potential impacts in Dade County of climate change and an increase in sea level on water supply, water control and drainage systems, building foundations, roads, bridges, airports, solid waste disposal sites, and sewage transport and treatment systems. The effects on operating costs for pumping and air conditioning and on the need for beach nourishment were not analyzed.

Preliminary analyses and estimates by local engineers and planners, which were undertaken at the request of the authors, formed the primary basis for the study. Further information was drawn from Rhoads et al. (1987) and from the Comprehensive Development Master Plan for Dade County.

The study provides only a preliminary examination of the issues and impacts. The best choices cannot be determined without engineering and cost analyses and detailed examination of local hydrologic impacts.

\section{Oceangates}

Greater Miami is bounded by water on all sides in the rainy season. An extensive network of canals and levees has been built to control ocean and fresh water flooding and to recharge the aquifer that lies beneath the area. One of the most porous aquifers in the world lies less than 1.5 meters below the surface in one third of the developed area of Miami. Because the aquifer extends under the ocean, the typical urban response to a rising sea - diking the water at the surface and pumping out the seepage from ditches behind the dikes - appears unworkable. Unless the dike were extended more than 45 meters underground, rising sea water pressure would cause the sea to rush into the aquifer below the surface and push fresh water almost to the surface.

A preliminary appraisal suggests that the best oceangate strategy might combine: 1) raising the land in lowlying areas; 2) upgrading levees and dikes with pumped outflows; 3)retreating from selected areas; and 4) increasing the fresh water head roughly in proportion to the rise in sea level to prevent salt water infiltration of the aquifer.

Canals, Levees, and Drainage

Based on extensive experience with comparable construction, a local expert estimated that the one-time capital cost of upgrading existing canals in response to a one-meter rise in sea level would be about $\$ 12$ million dollars because fill is virtually free. He estimated that almost \$50 million in new control structures, including extensive pumping capacity, would be required on the canals used to maintain the fresh water head. Large-scale pumping also would involve substantial operating costs. Extrapolation from the estimates in Weggel et al. (1989) suggests that an additional $\$ 48$ million might be devoted to raising levees and dikes. Storm sewers and drainage might 
need upgrading, requiring investment of several hundred million dollars above normal replacement costs. The Miami airport also might need roughly $\$ 30$ million in drainage improvement.

\section{Foundations of Houses and Streets}

Because the houses are built on concrete slabs, most buildings in newer areas already are on lots raised to meet the Dade County flood control ordinance. The foundations of larger buildings often already extend into the water table, and thus a local engineer believed that the foundations generally would remain stable if the fresh water head were raised one meter. Conversely, the water table could infiltrate the base of about a third of the streets in the County and these would have to be raised or risk collapse. If the sea level rose so gradually that the streets and related sewer mains could be raised during a scheduled reconstruction, a local official estimated that the added public cost might approximate $\$ 250$ million. Building owners would incur substantial costs to improve drainage, raise yards, raise lots at reconstruction, and pump sewage to mains. In addition, many houses would suffer aesthetically because they would be a meter below street level.

\section{Bridges}

A one-meter rise in the sea level would require raising most bridges to ensure adequate underclearance; to prevent erosion beneath abutments, lifting of steel and box culverts, and pavement failure in bridge approaches; and to reduce vulnerability to storm surges during hurricanes. A local official estimated that the cost of retrofitting would be much higher than the cost of modification during reconstruction which occurs typically on roughly a 50 -year cycle.

\section{Water Supply}

The climate change models suggest that rainfall could decrease by 10 to 15 percent in the dry winter months, although annual rainfall might increase in response to increased hurricane intensity and frequency. Calculations based on the models indicate that cooling degree days might increase about 50 percent, thus increasing the water loss associated with air conditioning. Because the scenarios suggest that winds would decrease, modeling by Diamond et al. (1988) indicates reduced evapotranspiration loss from the aquifer and surface storage areas.

If hurricanes increase, the added expense of supplying water for Miami might be only the cost of moving some wells farther inland. If they do not, the climate change could create water shortages and lead the city to start largescale water desalination. Conversely, increased hurricane frequency and intensity could cause billions of dollars in property damage.

\section{Other Temperature Effects}

Increased air conditioning use could require raising electric generating capacity by 20 percent (Linder, Gibbs, and Inglis, 1987). The sanitary sewer pipes in Miami could face increasing hydrogen sulfide corrosion if the temperature rose. It appears likely that there would be little effect on sludge treatment and solid waste disposal operations, although landfill subsidence might increase. Rising temperatures also would have minimal effects on local streets.

\section{Summary}

The analysis of the oceangate options for Miami provides insight into the likely impacts of increased sea level on cities built on coral reefs, but not effects on most coastal cities in the U.S. Dade County also is unusual because of the extensive availability of readily extracted fill on public lands with easy access to a canal system that can be navigated by flat-bottomed barges. Nevertheless this case study suggests that a global climate change could force large coastal MSAs to invest billions of dollars to add to and upgrade their infrastructure.

As table 1 shows, global climate change could require $\$ 0.5$ billion, and perhaps substantially more, in capital investment in Greater Miami.

\section{Cleveland Could Emerge a Winner}

The Cleveland case study examined the effects of a climate change on costs of snow and ice control, road construction and maintenance, heating and cooling, water supply, and storm and waste water transport. A preliminary analysis of the impacts of a 0.6 to 1.65 meter drop in the level of Lake Erie also was included.

\section{Snow and Ice Control}

Global climate change could cause the annual snowfall in Cleveland to drop from 1.25 to roughly 0.2 meters, reducing annual snow and ice control costs by about $\$ 4.5$ million. Further savings estimated at $\$ 700,000$ per year were projected to result from decreased frost damage to roads and bridges. The impact of the projected global climate change on annual snowfall was extrapolated from current weather patterns using the percentage change factors in the climate change models. The effect on the snow and ice control budget was based on an analogy to the 
Table 1

Estimated Infrastructure Investment Needs Created in Miami by Doubling Atmospheric $\mathrm{CO}_{2}$, in 1987 Dollars

\begin{tabular}{ll}
\hline \multicolumn{1}{c}{ Infrastructure } & \multicolumn{1}{c}{$\begin{array}{c}\text { Investment } \\
\text { (million) }\end{array}$} \\
\hline Raising Canals/Levees & 60 \\
Canal Control Structures & 50 \\
Pumping & not estimated \\
Raising Streets & 250 extra reconstruction cost \\
Raising Yards & not estimated \\
Pumped Sewer Connections & not estimated \\
Raising Lots at Reconstruction & not estimated \\
Drainage & $200-300$ \\
Airport & 30 \\
Raising Bridges & not est.; retrofit costs more than \\
raising at reconstruction \\
Sewer Pipe Corrosion & minimal \\
Water Supply & not estimated \\
Electric Capacity & $20 \%$ increase \\
\hline \hline
\end{tabular}

budget in Nashville, Tennessee. Due to data limitations, the analog city was selected on the basis of a 4 degree $C$ rise in temperature, although both weather models suggested a 5.5 degree rise.

\section{Heating and Cooling Costs}

Heating costs for public buildings could drop roughly \$2.3 million dollars per year in Cleveland. Conversely, public air conditioning costs could rise by $\$ 6.6$ to $\$ 9.3$ million per year.

The impacts on energy costs in public buildings were estimated from data on total energy consumption, by building, and the judgment of local experts about how much of the consumption was for heating and air conditioning. The change in costs was assumed to be proportional to the change in heating and cooling degree days suggested by the climate change models. Schools and city buildings where air conditioning probably would be added were identified using an inventory of heating and cooling capacity, by building. The cost of added capacity was based on a rough engineering rule of thumb.

If temperatures rose to the levels projected in the GFDL and GISS scenarios, Cleveland might spend about $\$ 65$ to $\$ 80$ million to add air conditioning to older schools and such larger non-office spaces as gyms and auto repair garages. Much of this expenditure would occur as buildings were replaced or refurbished and might have occurred even without a change in climate. The costs of adding air conditioning to buses as they are replaced should be minimal.

The analysis of changes in heating and cooling costs and cooling equipment needs was based on rules of thumb, not on detailed assessments of individual buildings. Consequently, the impacts are order-of-magnitude estimates. The analysis also omitted public housing and a few other classes of public buildings.

\section{Road Construction and Maintenance}

In estimating the impacts on weather-related road deterioration, the GFDL and GISS $2 \mathrm{XCO}_{2}$ scenarios were used to estimate the number of days per year that maximum temperatures would be below freezing. It was assumed that the number of deep freeze cycles would be reduced proportionately and an equation from AASTHO (1987) was used to estimate the percentage increase in the serviceability index of city streets. As a check on this estimate, the GFDL and GISS projections of winter temperature and precipitation were applied to estimate the climate band to which Cleveland would shift on the Moisture Accelerated Distress Index (Carpenter et al., 1981). Both indices provide measures of the impact of cold weather on pavement maintenance costs. Asphalt pavement thickness required during road construction and reconstruction also is a function of climate. The effect of changing weather on 
pavement thickness was estimated from the difference in the AASTHO Regional Factors (FHWA, 1983) for Cleveland and for Louisville, the winter analog city for Cleveland after climate change. Cost savings were estimated by combining estimated reductions in repair needs and reconstruction costs with data on average annual expenditure expected between 1987 and 1991.

The rise in winter temperatures associated with a doubling in $\mathrm{CO}_{2}$ would be expected to allow Cleveland to use thinner pavement. Savings of about 3 percent in road resurfacing costs and 1 percent in reconstruction costs might result. The net savings could average about $\$ 200,000$ per year, 1.3 percent of the 1988 capital budget for the city. A decrease in roadway maintenance costs of about 7 percent, or roughly $\$ 500,000$ per year, also seems likely.

\section{Water Supply and Navigation}

A climate-induced drop in the level of Lake Erie probably would not affect the Cleveland water supply adversely, according to local experts, but it could increase summer demand about 5 percent (Cohen, 1987). Dropping lake levels could require some dredging, especially in the Cuyahoga River. Keith et al. (1989) estimated the dredging costs at \$11 to \$29 million over the next century, depending on how severely lake levels drop. While gradually falling Great Lakes levels might not impose major costs, Changnon (1989) concluded from a study of the historical response of Chicago to changing lake levels that widely oscillating lake levels could.

\section{Sewer Capacity}

The GFDL and GISS $2 \mathrm{XCO}_{2}$ scenarios both suggest that the rainy season is unlikely to get wetter in Cleveland. Thus, an effective doubling of $\mathrm{CO}_{2}$ would appear unlikely to create a need in that city for upgrading the storm and waste water collection system.

Summary

Overall, the impacts of the projected global climate change on Cleveland probably would be modest and generally positive. The city climate should become more hospitable. Its location on Lake Erie should insulate the Cleveland metropolitan area from water supply problems, making it a more attractive location for water-intensive industry if water supplies in other areas become less reliable. Other Great Lakes cities could become more desirable places to live and the resulting in-migration could bring growth-related infrastructure costs and a rise in property values.

As Table 2 shows, the net direct impact on infrastructure costs of a doubling in $\mathrm{CO}_{2}$ could be negligible, although expenditures probably would shift between categories. In addition to the costs shown in Table 2, there could be a one-time capital expenditure of $\$ 68$ to $\$ 80$ million to add air conditioners in public buildings. Many homeowners also probably would add air conditioners.

If temperature should rise several degrees, Cleveland and most other Northern cities probably could anticipate savings in costs of snow and ice control, heating, and

Table 2

Estimated Effects of Doubling Atmospheric $\mathrm{CO}_{2}$ on Annual Infrastructure Costs in Cleveland, in 1987 Dollars

\section{Cost Category}

Change in Costs

Million

Heating
Air Conditioning
Snow \& Ice Control
Frost Damage to Roads
Road Maintenance
Road Reconstruction
Mass Transit
River Dredging
Water Supply
Storm Water System
Total

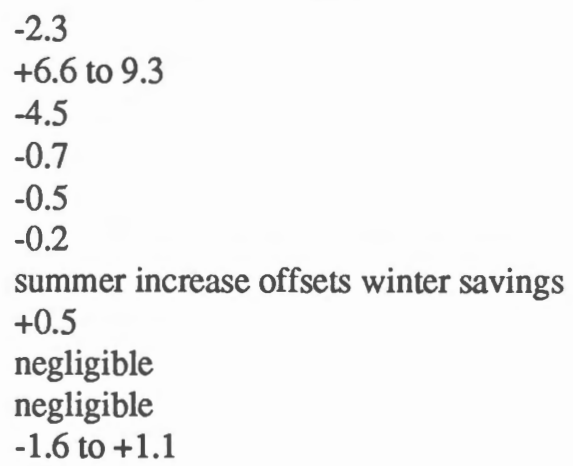


roadway construction and maintenance. These savings might approximately offset the increase in air conditioning costs. Communities south of Cleveland probably would experience modest budget increases. In the Midwest, however, primarily other Great Lakes cities would be likely to share freedom from water supply problems.

\section{New York City}

The infrastructure in New York City likely would be affected in many ways by the projected global climate change. The effects of a temperature change should be similar in New York City and Cleveland. Interpolating from data in Weggel et al. (1989) suggests that upgrading dikes and levees to counteract a one meter rise in the sea level might cost $\$ 85$ million over 100 years. In addition, the city might have to invest heavily to protect underground infrastructure from sea water infiltration.

A senior member of the New York City Office of Environmental Protection indicated that all sanitary and much storm sewage is pumped (Schwartz and Dullard, 1988). The roughly 450 outfalls use gravity flow into tidal areas. With a rising sea level, these outfalls would have to be inspected more frequently and the pumps might run more, but the official believed that the capacity and design of the system would not need revision. Nevertheless a higher sea level, could increase sewer backups, ponding, and basement flooding in a few low-lying areas when high tides coincide with high runoffs. The official noted that the city already has hedged against the possibility of a higher sea level by raising an outlet on a drainage structure for a water tunnel it is building.

Linder et al. (1987) suggest that increased air conditioning use could raise summer electric demand by 10 to 20 percent in the New York metropolitan area.

The most pressing, and perhaps the largest, problem facing the city may be coping with the impacts of a global climate change on the water supply. The New York City case study was restricted to that issue.

\section{Current Water Supply}

The New York metropolitan area draws water from the adjoining Hudson and Delaware River Basins and from underground aquifers that serve much of New Jersey and Long Island.

The water supply network is in deficit. The Mayor's Task Force (1987) preliminarily has recommended remedying the New York City portion of the deficit through better demand management and reactivation of a water intake at Chelsea. This would require a \$223 to \$391 million investment that would yield 375 to 750 million liters of water daily.

\section{Methods}

The work reported here focused on water balanceestimating the impacts of a doubling in atmospheric $\mathrm{CO}_{2}$ on water demand and on the net deficit that might result from an increased demand coupled with supply reductions caused by changing weather and a rising sea. For convenience, it was assumed that $\mathrm{CO}_{2}$ would double by 2030 , since water demand projections and supply plans extend only through that date. This assumption should affect the percentage changes in water supply and demand resulting from the doubling only minimally, although the absolute changes will be underestimated.

\section{Demand Impacts}

The scenarios of climate change suggested a rise in average temperatures in the New York area by 4 to 6.5 degrees $\mathrm{C}$ during most of the year, implying about a 20 percent increase in cooling degree days. Applying design standards and a non-residential mix factor to the electricity demands for air conditioning projected by Linder et al. (1987) produced an estimate that average daily summer demand for water for cooling large buildings could increase 190 million liters. Historical data on residential summer water use, by temperature level, (Morgan and Smolen, 1976) indicates that more intensive water use for lawn watering could raise demand 110 million liters per day. The aggregate estimated annual demand increase was about 5 percent.

\section{Supply Impacts}

Higher temperatures could increase evaporation and evapo-transpiration, decreasing the feasibility of storing water in surface impoundments. The impacts on reservoir supply were assumed to lie in the percentage range predicted by the water balance model developed by Cohen (1985) for the Great Lakes Basin-which adjoins the Hudson and Delaware River Basins - a supply loss ranging from 10 to 24 percent. A Hudson River basin water balance model run by New York City staff supported the 10 percent range for the GISS temperature and precipitation projections.

The salt water advance that projected increases in the sea level might cause on the Hudson was estimated by analogy to the Delaware (Hull and Titus, 1986) which has a comparable flow rate, rather than by geometric modeling. A one-meter rise in sea level could place the proposed $\$ 300$ million Chelsea intake below the salt line during the peak summer demand period in mild drought years, reducing supply another 13 percent. With a larger margin of error, it might prevent use of the existing Poughkeepsie intake 
during severe droughts, further reducing supply. In addition, subsurface infiltration would reduce the supply available from the Long Island aquifer.

These estimates are consistent with the opinions of a local water planner (Schwartz and Dillard, 1988) and with infiltration experience during a severe drought in 1982. Nevertheless, the study results should be interpreted only as order of magnitude estimates. More refined climatic and hydrologic modeling would be needed to support investment decisions.

\section{Implications}

In the aggregate, doubling atmospheric $\mathrm{CO}_{2}$ could produce a shortfall of 28 to 42 percent of planned water supply in the Hudson River Basin. Among the feasible alternatives evaluated by the Mayor's Task Force in 1987, the least expensive way to add that much capacity would be a $\$ 3$ billion project to skim Hudson River flood waters into additional reservoirs.

\section{National Policy Implications}

The uncertain, yet potentially imminent impact of global climate change already has increased the riskiness of infrastructure investments. Application of design standards and extrapolation from historical data may no longer provide reasonable assurance that water and power supply, dam strength and capacity, bridge underclearances, or storm sewerage capacity will be adequate for the 35-, 50-, and 100-year lives for which such facilities have been designed. The historical maps of the National Flood Insurance Program identifying the 100-year floodplain and 500 year floodway may no longer provide a reliable basis for local building and zoning ordinances designed to minimize flood losses of life and property. Migration in response to climate change could alter radically the population growth projections underlying capacity decisions about highway and wastewater treatment systems.

Corporate investment analysts have developed methods, including decision theory, portfolio analysis, and chance-constrained programming, to guide decision making under uncertainty. Infrastructure analysts at all levels of government might be wise to adapt these methods to their work. Especially in coastal areas, the possibility of accelerating global climate change soon may require careful decisions about how and when to adapt the infrastructure. A strong emphasis on life-cycle costing and the courage to make expensive improvements during reconstruction in anticipation of future changes could provide large cost savings.

\section{Water Supply and Use}

Water supply is of particular concern because decades are required to plan and complete projects which then may last 100 years. Dams, reservoirs, and water intakes already are being built that global climate may make obsolete or inadequate, and more are in the planning stages. Elsewhere, communities may be allowing development of land needed for reservoirs to meet the water shortages expected to result from climate change.

National policy intervention could be the best way to prevent expensive water supply mistakes and to adjust supplies in an orderly fashion. A sensible goal over the next ten years would be to study the projected impacts of a doubling of $\mathrm{CO}_{2}$ and of two sea level rise scenarios (perhaps 0.25 and 1 meter) on the water supply of every major metropolitan area. These studies would require localized models of the effects of global climate change on precipitation, runoff and water quality. They also would require analyses of geomorphology and probable salt water infiltration into most major coastal rivers and aquifers. At a minimum, planned U.S. Geological Survey studies such as the upcoming examination of the behavior of the salt front in the Hudson River should consider the potential impacts of a rise in sea level.

Water supply investments frequently affect multistate areas, creating a need for Federal coordination. The Supreme Court has settled water rights disputes on many major rivers in the past, and global climate change could generate new disputes. Cost-effective response to climate change also might require new multi-state water projects. For example, a major project on the Hudson River that allowed New York City to reduce its use of Delaware River water might be the least costly way to increase water supply in Philadelphia. The upcoming interstate debates over water supply financing should be informed by an important lesson of past infrastructure crises: water piping and pumping costs resulting from global climate change should be fully recovered from the water users to avoid stimulating artificial demand for bargain water.

Conservation also might merit increased emphasis. Many communities should consider emulating Tucson and recycling purified sewage effluent in lawn watering and cooling towers. As the growing season lengthens and 
temperatures rise, some existing landscaping materials will die off. Replacement with drought-resistant grasses, trees, and shrubs should be encouraged.

\section{Floodplain Development}

The ambitious flood-plain mapping efforts of the Federal Insurance Administration might beneficially consider global climate change. It might be more costeffective for coastal floodplain studies to assume a rise in sea level of 0.2 to 0.4 meters by 2040 , and to require floodproofing of new buildings on that basis. Prospective action might be easier and less expensive than protecting structures already built. In addition, including the costs of flood protection in construction costs could reduce economically unjustifiable overbuilding in future floodplains and ocean beds and avoid future demands for public subsidy of flood protection.

\section{Infrastructure Standards}

The voluntary organizations that promulgate engineering design standards might be well advised to educate their committees about potential global climate change. Growing uncertainty about future temperature, precipitation, and sea levels might dictate reassessment of existing standards and safety factors for ventilation, drainage, flood protection, facility sitting, expansion capability and resistance to corrosion. Conversely, prompt detection of changes expected to last would allow adjustment of geographically based standards - e.g., on roadbed depth and home insulation levels - and provide significant savings. Thus, the standard-making organizations might wish to establish how and when their committees should account for global climate change or educate their committees about the prospects for such change.

Infrastructure Needs Assessments and Coordination of Oceangate Investment

Congress has mandated regular reports on many types of infrastructure needs. On a one-time or routine basis, these reports could examine the sensitivity of the needs estimates to climate change. The Federal Highway Administration might save money by encouraging states to raise some bridges on the Federal-Aid Highway System prospectively during reconstruction rather than risk sea level rise. EPA might examine the likely impacts of climate change on its assessments of storm sewer needs and related water quality issues. Falling river levels, for example, might require increased sewage treatment capacity for cities to comply with the effluent discharge rates prescribed in variable-flow permits. The Corps of Engineers might examine the potential implications of climate change for dam safety. The Office of Management and Budget also might discuss potential climate change impacts in the capital investment supplement to the annual Federal budget.

Designation of a lead agency for oceangates also might be helpful. Increasingly, information may be needed on oceangate technology, the nature and condition of the existing oceangate inventory, and methods of financing. Development of a small unit with expertise in the area could facilitate information flow and provide a base for quick launching of major coastal defense efforts if they should be required.

\section{Recommendations for Further Research}

It could cost billions of dollars to meet the increased water supply needs associated with global climate change. Research on technological change that might reduce these costs seems to be an important priority. The possibilities include:

-Examining whether the engineering options and cost outlook for desalination have changed since the research program of the Department of Interior ended in the 1970's;

-Redesigning cooling towers to cut evaporation losses;

-Examining the feasibility, environmental implications and cost-effectiveness of installing barriers to slow or prevent salt water infiltration into coastal rivers and aquifers during droughts.

More examination also is needed of urban effects generally. No one knows the probable impacts of global climate change on urban subsidence problems, for example in Phoenix. Impacts on inland and West Coast cities have not been examined. The potential for probable consequences of salt water infiltration into pipes, especially in older coastal communities, should be assessed.

Research on urban oceangates should be intensified. Cost-benefit analyses of preventive versus remedial strategies are needed. How substantially, for example, are the need for and costs of oceangates likely to be reduced by reassessing the floodplain maps every decade to incorporate best estimates of sea level rise over a 40 - to 50 -year time horizon and to ensure that lots will be raised or floodproofed during construction? What mapping costs and changes in construction costs would result? 
It also would seem worthwhile to examine the probable impacts of global climate change on domestic and international employment and migration flows, and the infrastructure demands these flows produce. Some areas might become so dry or hot that people would move away, while others might flourish. New investment in water supply, for example, might be unnecessary in areas that lose population, but extra capacity might be needed in areas where the population grows. Similarly, as climate change shifts the bestareas for growing specific crops, new farm-to-market transportation networks might be needed. Rights-of-way for these systems might best be set aside now, before land prices rise in response to climate change.

Finally, urban infrastructure planners and engineers need practical guidelines that describe how to analyze the potential local impacts of global climate change and make strategic infrastructure decisions. Uncertainty about the changes that are coming, when they will occur, and the technological changes that will occur in the interim make time-phased infrastructure planning very difficult. Models for assessing the risks of too much and too little action would facilitate such decisionmaking.

\section{Acknowledgements and Disclaimer}

The work described herein was supported by EPA Cooperative Agreement CR-814883-01-0 with The Urban Institute. The opinions expressed and any errors are the responsibility of the authors.

\section{References}

AASHTO. 1987. American Association of State Highway and Transportation Officials. Manual for the Design of Permanent Structures, Appendix A. Treatment of Roadbed Swelling and/or Frost Heave in Design. Washington, DC: American Association of State Highway and Transportation Officials.

Bruske, Ed. 1988. "104 (Phew) Degrees Hottest in 52 Years," The Washington Post 111:225, July 17, pp. Al, A6.

Carpenter, Samuel H., M. I. Darter, G.J. Dempsey and Stan Herrin. 1981. "A Pavement Moisture-Accelerated Distress (MAD) Identification System," Vols. 1 and 2, FHWA/RD81/079, September.

Changnon, Stanley A., Steven Leffler and Robin Shealy. 1989. "Impacts of Extremes in Lake Michigan Levels along Illinois Shorelines: Low Levels," Appendix Report in EPA Global Climate Change Report to Congress.

Cohen, StewartJ. 1987. "Projected Increases in Municipal Water Use in the Great Lakes Due to $\mathrm{CO}_{2}$-induced Climatic Change," Water Resources Bulletin 23:1, pp. 91-101.

Comprehensive Development Master Plan for Metropolitan
Dade County. Florida. July 1979, Amended July 1985 and June 1987. Metropolitan Dade County Planning Department.

Diamond, Craig, Jill Jeglie and Mark T. Brown. 1988. "Water Management Implications of the Greenhouse Effect in South Florida," Report to EPA from FAU-FIU Joint Center for Environmental and Urban Problems, Fort Lauderdale, F1.

Federal Highway Administration. 1983. "Section 137 Studies: Climate and Apportionment and Interstate 4R Apportionment," prepared for the United States Congress.

Hirsch, J. 1988. "As Streets Melt, Cars Are Flummoxed by Hummocks," The New York Times 137 (47599). August 16, pp. B1, B5.

Hull, C.H.J., and James G. Titus, ed. 1986. Greenhouse Effect. Sea Level Rise, and Salinity in the Delaware Estuary, US Environmental Protection Agency 230-05-86-010.

Jenne, Roy. 1988. National Center for Atmospheric Research, Personal Communications and Mailings to EPA Climate Change Grantees.

Kalkstein, Laurence S. 1989. "The Impact of Carbon Dioxide and Trace Gas-Induced Climate Changes upon Human Mortality," Appendix Report in EPA Global Climate Change Report to Congress.

Keith, Virgil F., Carlos De Avila, and Richard M. Willis. 1989. "Effect of Climatic Change on Shipping Within Lake Superior and Lake Erie," Appendix Report in EPA Global Climate Change Report to Congress.

Lewis, Nancy. 1988. "Two More Heat Records Fall as Summer of 1988 Boils On," The Washington Post 111:257, August 18 , pp. A1, A10, A11.

Linder, Kenneth P., Michael J. Gibbs, and Mark R. Inglis. 1987. Potential Impacts of Global Climate Change on Electric Utilities, ICF Incorporated 824-CON-AEP-86.

Mayor's Intergovernmental Task Force on New York City Water Supply Needs. 1987. "Managing for the Present, Planning for the Future."

Morgan, W. Douglas, and Jonathan C. Smollen. 1976. "Climatic Indicators in the Estimation of Municipal Water Demand," Water Resources Bulletin 12:3, pp. 511-515.

Rhoads, P. B., G.C. Shih and R.L. Hamrick. 1987. "Water Resource Planning Concerns and Changing Clmiate: a Florida Perspective." In Proceedings of the Symposium on Climate Change in the Southern United States: Future Impacts and Present Policy Issues. Norman, OK, University of Oklahoma, pp. 348-363.

Schwartz, Harry E., and Lee Dillard. 1988. "Chapter III-D Urban Water," in AAAS Global Climate Change Report, Washington DC.

Smith, Joel B., and Dennis A. Tirpak. 1989. The PotentialEffects of Global Climate Change on the United States, Report to Congress, U.S. Environmental Protection Agency.

Sossaman, Bruce A. 1988. News Release, US Army Corps of 
Engineers, New Orleans District. 1988. News Release, US Army Corps of Engineers, New Orleans District, July 15.

"Warped Rails Checked in Amtrak Wreck," The Washington Post 111:246, August 7, 1988, p. A5.

Weggel, J. Richard, Scott Brown, Juan C. Escajadillo, Patrick
Breen, and Edward L. Doheny. 1989. "The Cost of Defending Developed Shorelines along Sheltered Waters of the United States from a Two Meter Rise in Mean Sea Level," Appendix Report in EPA Global Climate Change Report to Congress. 